\title{
Extreme oncoplasty for centrally located breast cancer in small non-ptotic breasts: extending the indications of chest wall perforator flaps with areolar reconstruction
}

\author{
Shashank Nigam ${ }^{1,2}$, Andrew Eichholz ${ }^{3}$, Madhu Bhattacharyya ${ }^{4}$, Vaishali Parulekar ${ }^{4}$ and Pankaj Gupta Roy ${ }^{1}$ \\ ${ }^{1}$ Department of Breast Surgery, Oxford University Hospitals NHS Foundation Trust, Oxfordshire OX3 7LF, UK \\ ${ }^{2}$ Private Oncology Clinic, Lucknow, UP 226021, India \\ ${ }^{3}$ Department of Oncology, Oxford University Hospitals NHS Foundation Trust, Oxfordshire OX3 7LF, UK \\ ${ }^{4}$ Oxford Breast Imaging Centre, Oxford University Hospitals NHS Foundation Trust, Oxfordshire OX3 7LF, UK
}

\section{Abstract}

Background: Breast cancers located centrally require excision of nipple-areola complex. A simple central wide excision is a safe option but results in suboptimal aesthetic outcome. An oncoplastic option involves therapeutic mammoplasty with or without areolar reconstruction, limited to moderate and large ptotic breasts. For small non-ptotic breasts, most surgeons would resort to mastectomy with/without reconstruction.

Methods: Lateral chest wall perforator flap (CWPF) is an option for partial breast reconstruction in small to moderate sized, non-ptotic breasts for laterally located tumours. We have extended the application of CWPF for central tumours to avoid mastectomy in selected patients.

Results: We here present a case series of four patients with small to medium-sized nonptotic breasts, who had centrally located breast cancer or ductal carcinoma in-situ (DCIS). Three patients had single stage CWPF reconstruction, and one had central excision with immediate reconstruction following a failed attempt at therapeutic mammoplasty. All had the areola reconstructed using flap skin; one patient had simultaneous nipple reconstruction.

Conclusions: CWPF is an option for treatment of centrally located breast cancers/ DCIS needing nipple-areola complex excision for patients wishing to avoid mastectomy. Patients with small to medium-sized non-ptotic breasts are suitable, and need to be carefully selected.

Keywords: chest wall perforator flap, partial breast reconstruction, central excision, volume replacement oncoplastic breast surgery, centrally located breast cancer, extreme oncoplasty

\section{Introduction}

Breast conserving surgery (BCS) with adjuvant breast radiotherapy is the standard of care for early breast cancer. Trials have shown equivalence of this treatment to mastectomy

Correspondence to: Shashank Nigam Email: shashank.n13gmail.com

ecancer 2021, 15:1311

https://doi.org/10.3332/ecancer.2021.1311

Published: 01/11/2021

Received: 23/07/2021

Publication costs for this article were supported by ecancer (UK Charity number 1176307).

Copyright: $($ the authors; licensee ecancermedicalscience. This is an Open Access article distributed under the terms of the Creative Commons Attribution License (http:// creativecommons.org/licenses/by/4.0), which permits unrestricted use, distribution, and reproduction in any medium, provided the original work is properly cited. 
with respect to survival and local disease control [1-5]. It leads to improved quality of life, high patient satisfaction and good cosmetic results $[6,7]$. Indications for BCS have gradually been extended for larger tumour to breast ratio, or for tumours located at difficult sites by incorporating plastic surgery techniques to perform either volume displacement or replacement surgery [8, 9]. Oncoplastic breast surgery (OBS) has been found to be oncologically safe both for invasive and in-situ carcinoma, and results in better aesthetic and psychological outcomes [10-14]. Tumour location is an important factor influencing choice of oncoplastic technique.

Between $5 \%$ and $20 \%$ of breast cancers are located centrally [15-18]. Historically these have been treated with mastectomy. The oncological safety of BCS to treat centrally located breast cancer has now been established [17, 19-21]. Centrally located breast cancer requires excision of the nippleareola complex for oncological reasons [22]. A simple central wide excision with removal of the nipple-areola complex is oncologically safe and adequate (once complete resection is established histologically), however it results in residual breast which aesthetically looks suboptimal [23, 24].

Therapeutic mammoplasty with or without areolar reconstruction has been used to treat centrally located breast cancers with good outcomes [24-33]. It is usually indicated for moderate to large ptotic breasts and often necessitates contralateral symmetrisation surgery [12, 34]. For small to moderate sized non-ptotic breasts presenting with centrally located breast cancer, this option is limited and most surgeons would resort to mastectomy with or without reconstruction.

The evolution of OBS has seen various surgical techniques being employed for partial breast reconstruction in an attempt to improve the aesthetic outcomes and reduce mastectomy rates. Volume replacement using chest wall perforator flap (CWPF) is one such procedure, initially used by Holmström and Lossing et al [35], and later popularised by Hamdi et al [36-38]. These flaps are based on perforators supplying the lateral chest wall; namely lateral intercostal artery perforators (LICAP), lateral thoracic artery perforator (LTAP) and thoraco-dorsal artery perforators. This approach utilises the redundant lateral chest wall fold for reconstructing the partial breast defect resulting from excision of laterally placed tumours in small to moderate sized non-ptotic breasts. With increasing experience, surgeons have extended its indications. It is associated with minimal procedure-related morbidity, quick recovery and excellent aesthetic outcomes [39, 40]. The surgical technique and pre-operative marking are detailed in the previously published paper [41].

\section{Objectives}

We report challenging cases of centrally located breast cancers with nipple involvement or proximity to nipple necessitating excision of nipple-areola complex. The defect after wide local excision was reconstructed using the tissue from the CWPF and areola was reconstructed using the flap skin.

\section{Materials and methods}

These women had small to moderate sized non-ptotic breasts with relatively high tumour to breast ratio, as judged by imaging (multifocal cancer or extensive ductal carcinoma in-situ (DCIS)). All these women were keen to avoid mastectomy, thus partial breast reconstruction was performed using LICAP and/or LTAP based flap. The CWPF was tunnelled deep to the native breast tissue on the lateral aspect and then folded to ensure adequate volume to fill the defect, such that skin was oriented anteriorly, after folding, to reconstruct the areola. The resultant tunnelling led to fullness on the lateral aspect of breast but that did not seem to be of significant concern and did not result in significant asymmetry after radiotherapy. The aesthetic outcome was assessed by the clinical team using Harris scale (scale from 1 to 5) in the out-patient clinic between 1 and 3 years post-radiotherapy. All these women had ER positive, Her-2 negative breast cancer and received adjuvant treatment as per Multidisciplinary Team discussion. These cases took between 2 and 3 hours to operate and patients were discharged home the day after surgery. These patients encountered no significant complications, and no delay in adjuvant therapy was observed. One patient required margin re-excision and all patients received adjuvant radiotherapy. All patients have completed at least 1-year follow-up and are happy with the aesthetic outcome.

\section{Results (clinical and treatment details)}

Case 1: This lady was identified to have bifocal breast cancer in her left breast on her first screening mammogram at the age of 50 . She was on hormone replacement therapy. There were two areas, one measuring $24 \mathrm{~mm}$ just lateral to the left nipple (with nipple tethering), 
grade I invasive cancer on core biopsy. The second lesion was $15 \mathrm{~mm}$ in the upper outer quadrant (17 $\mathrm{mm}$ away from the first lesion), confirmed to be grade II invasive cancer on biopsy. The total extent was $54 \mathrm{~mm}$ in the cranio-caudal plane and $30 \mathrm{~mm}$ in the medio-lateral plane. Both the tumours were oestrogen receptor (ER) 8, progesterone receptor (PR) 8 and human epidermal growth factor receptor (Her-2) negative.

The patient had symmetrical breasts with a bra size of 32B. There was a prominent fold of tissue excess on the lateral chest wall, rendering CWPF as a potential option. She was offered mastectomy with immediate reconstruction, as the total size of the two cancers together made $\mathrm{BCS}$ a borderline option. The patient preferred to have breast conservation; therefore, staged approach to partial breast reconstruction was discussed. Patient chose to have one stage approach after careful deliberation, accepting the option of simple mastectomy if BCS was not successful. She had central wide excision and sentinel node biopsy with single stage partial breast reconstruction using LICAP flap with neoareolar inset using the skin from the lateral chest wall.

Histopathology confirmed bifocal invasive grade 2 cancer measuring 16 and $25 \mathrm{~mm}$, with intermediate grade (IG) DCIS. The whole tumour size was $60 \mathrm{~mm}$, and was excised with clear margins (superior margin being closest, $1 \mathrm{~mm}$ away). The sentinel node removed was positive for macrometastasis ( $6 \mathrm{~mm}$ tumour deposit) with no extra-capsular spread. Histopathological examination of the nipple showed DCIS $2 \mathrm{~mm}$ from the skin surface. She was recommended adjuvant chemotherapy, radiotherapy to breast (with tumour bed boost), axilla and supra-clavicular fossa along with endocrine therapy. She consented to enter the POSNOC trial [42] and was randomised to systemic therapy alone with no further local treatment to the axilla. The post-operative period was uneventful with no complications. The patient was very pleased with the outcome. She continues on Anastrozole with good tolerance.

Case 2: A 72-year-old lady presented symptomatically with left sub-areolar lump. This was occult on mammogram and ultrasound. A clinical core biopsy confirmed grade 2 invasive lobular carcinoma (ILC). The tumour was ER8, PR8 and Her-2 negative. MRI of breasts suggested a unifocal lesion measuring $26 \mathrm{~mm}$. She was fit and well with an active lifestyle. She declined the option of central wide local excision with therapeutic mammoplasty, as she did not wish asymmetry or need for external prosthesis and was keen to avoid contralateral breast surgery. She agreed to central wide local excision and immediate partial breast reconstruction with CWPF with sentinel node biopsy. She underwent simultaneous nipple reconstruction.

Histopathology revealed bifocal grade 2 invasive lobular cancers measuring 26 and $8 \mathrm{~mm}$ within high grade (HG) DCIS, total extent of DCIS was $50 \mathrm{~mm}$. The inferior margin was focally involved with DCIS. One out of two sentinel nodes showed evidence of macrometastasis (10 $\mathrm{mm}$ tumour deposit, without extra-capsular spread). The inferior margin was re-excised a few weeks later; access was gained via peri-areolar scar. No further disease was seen on histology. Her recovery was uneventful and there were no complications with full healing of the reconstructed nipple. She declined participation in the POSNOC trial [42] hence received treatment to axilla in line with standard treatment protocols in our centre. It was decided to avoid axillary node clearance in favour of axillary radiotherapy.

Breast multidisciplinary team recommended adjuvant radiotherapy to breast, axilla and supraclavicular fossa (SCF) with endocrine therapy. The National Health Service (NHS) PREDICT suggested 4\% survival benefit with third-generation chemotherapy at 10 years, therefore OncotypeDX testing was recommended, which reported a low recurrence score of 11 , suggesting very small benefit from chemotherapy. She was advised Anastrozole as endocrine therapy. She was reviewed in clinic a year after radiotherapy and has achieved an excellent aesthetic outcome with regard to size/shape of breast and symmetry (Figure 1).

Case 3: A 40-year-old lady was evaluated in a symptomatic clinic for a lump corresponding to a $35 \mathrm{~mm}$ mass on mammogram without calcifications in the lower outer quadrant of breast. This mass measured $22 \mathrm{~mm}$ on ultrasound, while axillary nodes were normal. Core biopsy confirmed grade 3 invasive ductal carcinoma (IDC) with HG DCIS. Receptor profile was ER8, PR6 and Her-2 negative. This lady had difficult family circumstances and was caring for a disabled family member. She was offered breast conservation with vertical scar therapeutic mammoplasty and sentinel node biopsy.

The histopathology showed $35 \mathrm{~mm}$ of invasive ductal cancer associated with extensive HG DCIS with a total tumour extent of $60 \mathrm{~mm}$. Lymphovascular invasion was present. A separate medial shave sent during surgery showed the presence of DCIS within $1 \mathrm{~mm}$ from the final margin. The single sentinel node removed showed micrometastasis with a tumour deposit of $1 \mathrm{~mm}$. As the medial margin was the margin adjacent to nipple, re-excision of this margin mandated a central nipple-areola excision. She was, therefore, offered mastectomy with reconstructive options due to presence of extensive, non-calcified DCIS, the extent of which was impossible to estimate with the available imaging. 

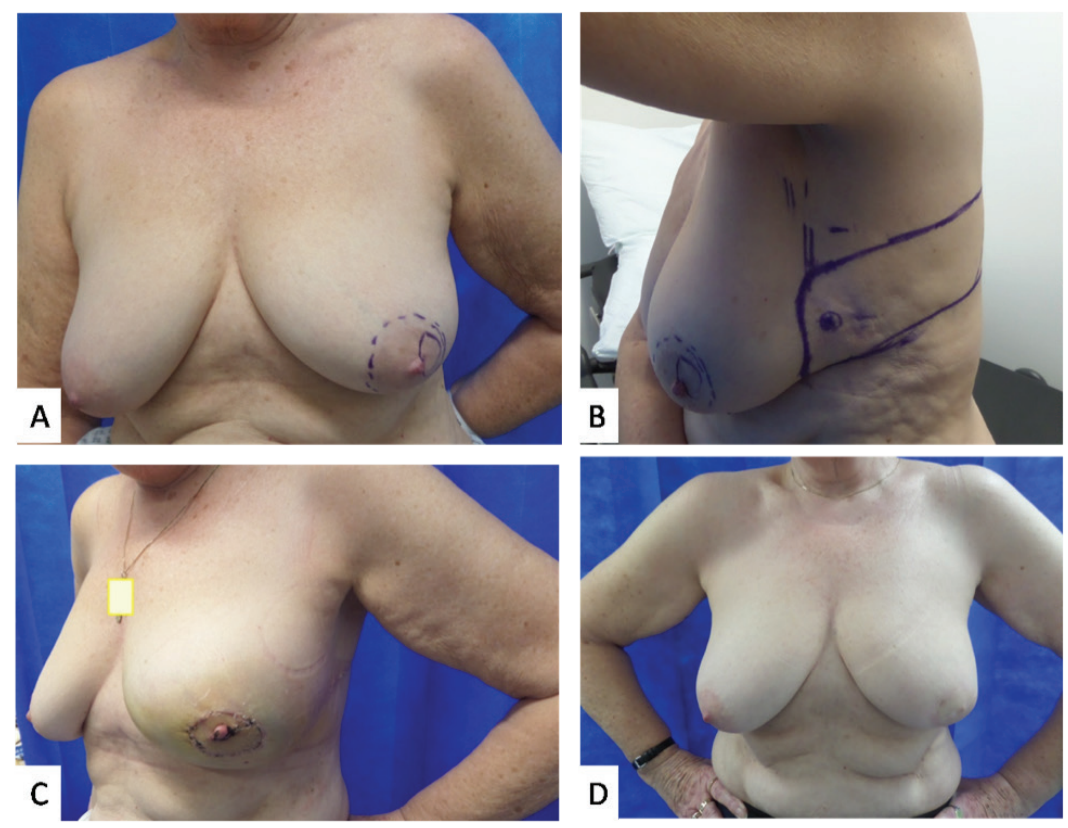

Figure 1. Photographs of case 2. (a): Marked sub-areolar lump with dashed markings for proposed central excision. (b): Lateral view showing the markings of CWPF with cross marked at perforator as identified using a handheld Doppler. (c): 2 weeks post-operative results showing reconstructed central defect with nipple and areolar reconstruction from skin of the flap. (d): 1 year post surgery and post radiotherapy results.

A decision was made in favour of adjuvant chemotherapy with a plan to do a completion mastectomy following chemotherapy. She was not keen for autologous reconstruction due to the extent of surgery and the recovery period involved. Implant reconstruction was considered suboptimal in light of the recommendation for adjuvant radiotherapy. The patient was very keen to consider the possibility of BCS. Upon reviewing her surgical options post chemotherapy and noting the limited choices available, she was offered an attempt at breast conservation by performing a central excision and partial breast reconstruction with a CWPF and neo-areolar inset. She understood that if this were to fail on account of finding more extensive disease, she would be recommended mastectomy. She underwent the proposed procedure and the histology did not reveal any residual malignancy. Following second surgery, her affected breast looked bigger than the opposite breast, this settled following radiotherapy to the whole breast with a boost to the tumour bed. She continues on Tamoxifen and is very pleased with the aesthetic outcome achieved (Figure 2).

Case 4: A 36-year-old lady was assessed in a symptomatic breast clinic for unilateral single duct nipple discharge. Ultrasound did not reveal any focal pathology, while the nipple discharge cytology showed epithelial cells suggesting an epithelial lesion. She had total duct excision. Histology revealed $6 \mathrm{~mm}$ of grade1 incidental mucinous carcinoma with $17 \mathrm{~mm}$ of HG DCIS, with DCIS involving the margins. The tumour was ER 8, PR 5 and Her-2 negative. She was recommended therapeutic surgery.

She was slim and small breasted with a bra cup of AA, but there was some redundant tissue on the lateral chest wall. Patient declined mastectomy, therefore BCS with partial breast reconstruction was offered as a potential alternative.

She underwent central wide local excision and sentinel node biopsy with partial breast reconstruction using a CWPF with neo-areolar inset. Central excision specimen showed a further $3 \mathrm{~mm}$ of grade 2 mucinous carcinoma with HG DCIS. This was excised with clear margins, with the closest peripheral margin being more than $10 \mathrm{~mm}$. She made a good recovery and received adjuvant whole breast radiotherapy. She continues on Tamoxifen and is very pleased with the aesthetic outcome.

The clinico-pathological and treatment details of these patients have been summarised in Tables 1 and 2, respectively. 

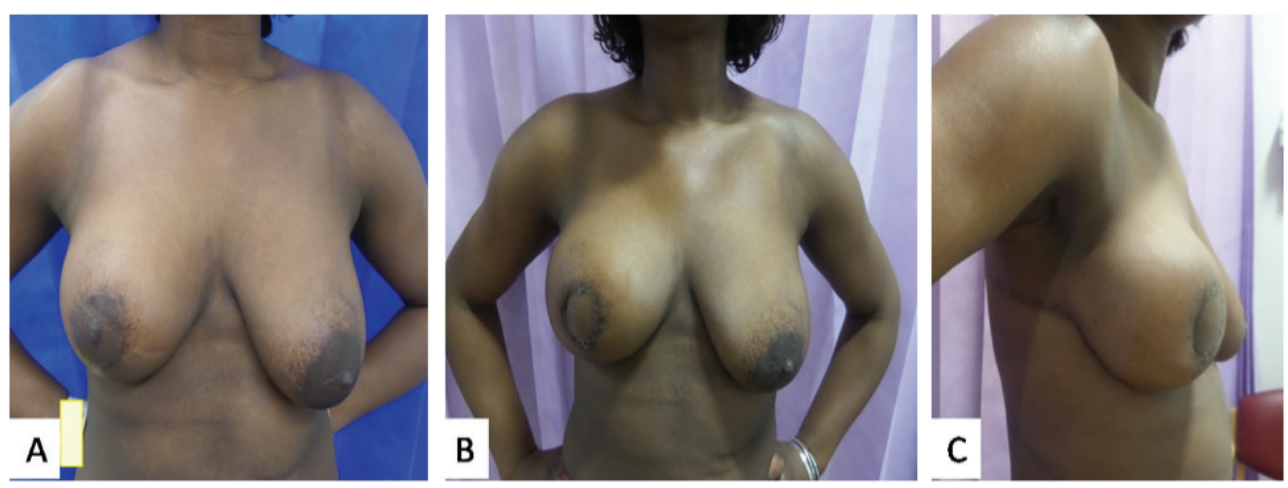

Figure 2. Photographs of case 3. (a): Approximately 6 months following a right vertical scar therapeutic mammoplasty for tumour located in the lower outer quadrant. The total tumour extent was $60 \mathrm{~mm}$ with DCIS close to medial margin. She completed adjuvant chemotherapy with a plan for mastectomy thereafter. As she was still keen on conserving her breasts, a central wide excision and partial breast reconstruction using CWPF were performed. (b and c): Front \& lateral view of 3 weeks post-operative results showing reconstructed central defect with areolar reconstruction from skin of the flap.

Table 1. Summary of cases with clinico-pathological details.

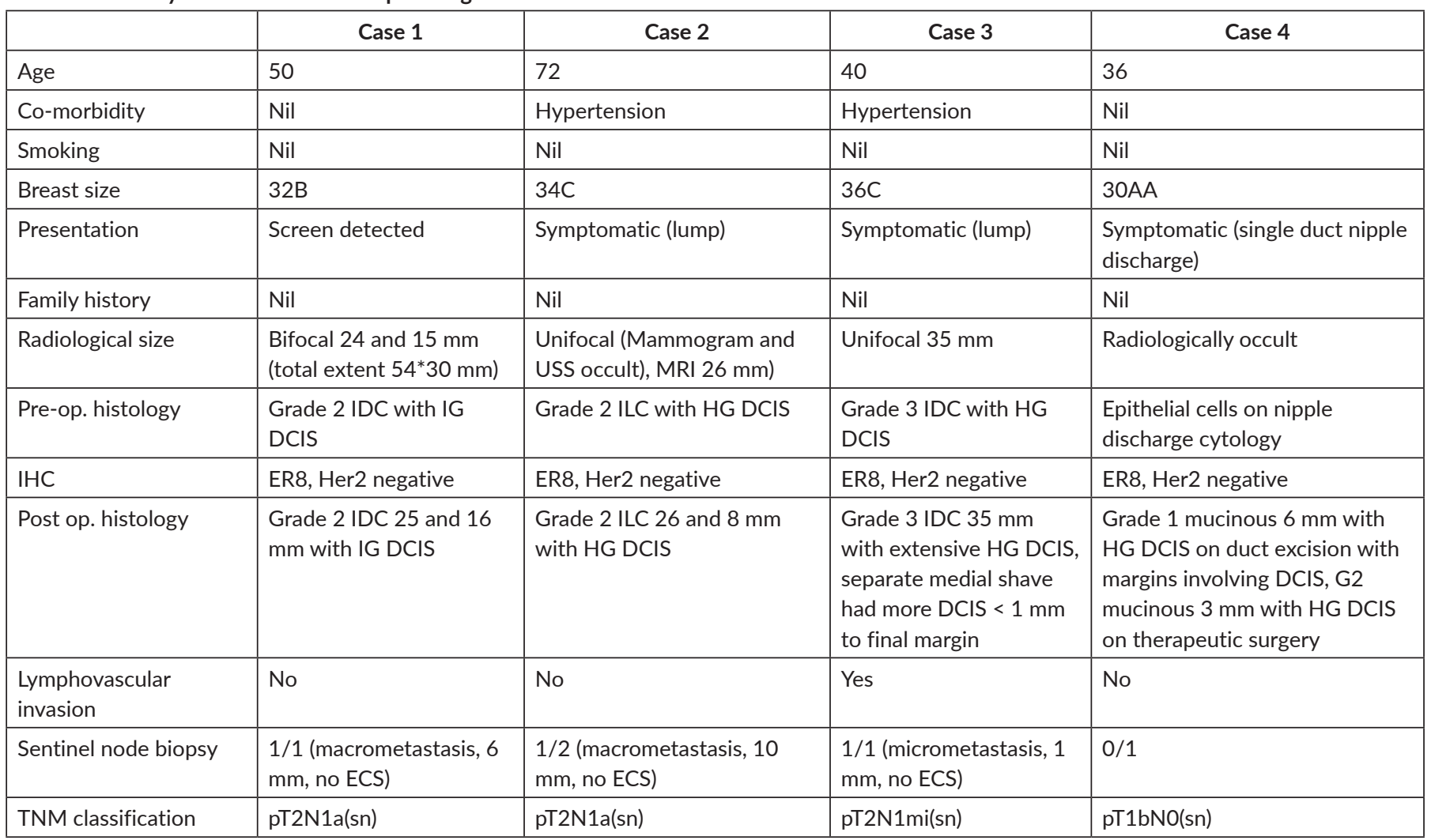

IDC, Invasive ductal carcinoma, no special type; ILC, Invasive lobular carcinoma; DCIS, Ductal carcinoma in-situ; IG, Intermediate grade; HG, High grade; ECS, Extracapsular spread; USS, Ultrasound scan; IHC, Immunohistochemistry 
Table 2. Summary of cases with treatment details.

\begin{tabular}{|c|c|c|c|c|}
\hline & Case 1 & Case 2 & Case 3 & Case 4 \\
\hline $\begin{array}{l}\text { Reason to excise nipple- } \\
\text { areola complex }\end{array}$ & Nipple tethering & Sub-areolar lump & $\begin{array}{l}\text { Involved medial margin on vertical } \\
\text { scar therapeutic mammoplasty - } \\
\text { adjacent to nipple }\end{array}$ & $\begin{array}{l}\text { Incidental cancer on duct } \\
\text { excision for nipple discharge }\end{array}$ \\
\hline Whole tumour size (in mm) & 60 & 50 & 60 & 17 and 6 \\
\hline Further axillary treatment & $\begin{array}{l}\text { No further treatment } \\
\text { arm of POSNOC trial }\end{array}$ & Axillary Radiotherapy & Nil & Nil \\
\hline Specimen weight (in gm) & 145 & 82 & $\begin{array}{l}170 \text { therapeutic mammoplasty } \\
52 \text { central excision }\end{array}$ & $\begin{array}{l}8.5 \text { total duct excision } \\
35 \text { central excision }\end{array}$ \\
\hline $\begin{array}{l}\text { Specimen dimensions } \\
(\mathrm{ML} \times \mathrm{AP} \times \mathrm{SI}) \mathrm{mm}\end{array}$ & $86 \times 75 \times 40$ & $77 \times 25 \times 65$ & $\begin{array}{l}80 \times 70 \times 45 \\
40 \times 35 \times 62\end{array}$ & $\begin{array}{l}45 \times 30 \times 15 \\
55 \times 40 \times 43\end{array}$ \\
\hline Surgical margins & Clear & $\begin{array}{l}\text { Inferior margin focally } \\
\text { involved with DCIS: } \\
\text { re-excised - no further } \\
\text { malignancy }\end{array}$ & $\begin{array}{l}\text { NA (No further malignancy seen on } \\
\text { central excision) }\end{array}$ & Clear \\
\hline Closest peripheral margin & $1 \mathrm{~mm}$ (superior) & $>5 \mathrm{~mm}$ & $>5 \mathrm{~mm}$ (medial) & $10 \mathrm{~mm}$ \\
\hline $\begin{array}{l}\text { Duration of surgery (in } \\
\text { min) }\end{array}$ & 140 & 110 & 120 & 110 \\
\hline Adjuvant chemotherapy & Yes & $\begin{array}{l}\text { No. Oncotype RS } 11 \\
\text { (NHS PREDICT } 4 \% \text { for } \\
\text { third generation) }\end{array}$ & $\begin{array}{l}\text { Yes, following vertical scar } \\
\text { therapeutic mammoplasty }\end{array}$ & No \\
\hline Adjuvant radiotherapy & $\begin{array}{l}\text { Yes (breast with boost) } \\
\text { - POSNOC no axillary } \\
\text { RT }\end{array}$ & Yes (breast, axilla, SCF) & Yes (breast with boost) & Yes (breast) \\
\hline $\begin{array}{l}\text { Adjuvant endocrine } \\
\text { therapy }\end{array}$ & Yes (Anastrozole) & Yes (Anastrozole) & $\begin{array}{l}\text { Yes (Tamoxifen). Declined } \\
\text { Zoladex, aromatase inhibitor and } \\
\text { bisphosphonate }\end{array}$ & Yes (Tamoxifen) \\
\hline Wound complication & Nil & Nil & Nil & Nil \\
\hline Shoulder function recovery & Complete & Complete & Complete & Complete \\
\hline Aesthetic outcome & Very good & Excellent & $\begin{array}{l}\text { Excellent (right bigger than left pre } \\
\text { radiotherapy) }\end{array}$ & Excellent \\
\hline
\end{tabular}

ML, medio-lateral; AP: antero-posterior; SI, supero-inferior; NA: not applicable; RS, recurrence score; RT, radiotherapy

\section{Discussion}

Centrally located cancers have traditionally been treated with mastectomy; however, in the era of oncoplastic surgery, it would be inappropriate to offer mastectomy purely due to location of tumour. Small central tumours could be managed with simple central wide local excision and primary closure. Various closure techniques have been attempted including purse-string, vertical or horizontal closure [24, 43]. This often leads to sub-optimal cosmetic results due to loss of breast volume and projection, although these options may be acceptable to some patients. Therefore, it is reasonable to offer the simple option to patients not wishing to undergo complex surgery or who are otherwise high risk for anaesthesia. 
Volume displacement oncoplastic techniques advocated for central cancers include Grisotti's infero-lateral dermo-glandular flap, mammoplasty with inferior dermo-glandular flap or melon-slice mammoplasty. These techniques either rely on creating neo-areola from patch of skin located inferior/infero-lateral to nipple-areola, or simply closing the breast in a way that maintains the shape of breast [16, 25, 26, 29, 32, 44, 45]. Galimberti et al [30] first described the infero-lateral dermo-glandular flap, which was later popularised by Grisotti et al [24]. However, most of these techniques are applicable mostly to moderate or large ptotic breasts. These procedures often necessitate contralateral symmetrisation surgery.

Volume replacement technique for central tumours described in the literature involves partial breast reconstruction using a latissimus dorsi flap [26, 46-51], which adds significant muscle morbidity. Other techniques of volume replacement like use of omental flap [52] or free dermal fat graft [43] have not been easy to reproduce and can have a significant risk of complications.

CWPF has been increasingly used in the last decade for treatment of laterally placed breast cancers in small to moderate sized nonptotic breasts [36]. They have been shown to be oncologically safe with low morbidity and good recovery of shoulder function and do not involve muscle morbidity [36, 39, 53]. When compared with mastectomy and reconstruction, CWPF offers quicker recovery, lower complication rates and better aesthetic results [38, 39, 41]. With increasing experience, longer flaps can be reliably raised based on LICAP and LTAP to reach central quadrants defects for breast cancer management. The skin inset to create areola is usually from the distal half of the flap providing an option to monitor flap vascularity in the post-op period, helping to improve operator's confidence.

It has been shown that these flaps do not interfere with radiological surveillance, and recall rates for biopsy are low [54, 55]. The flap is tunnelled into the defect behind the breast tissue, ensuring that residual breast tissue sits in front of the flap, thus avoiding the potential hindrance from the flap to allow detection of local recurrence in the future. The caveat with this approach is the risk of inadequate excision similar to other BCS approaches. If there is uncertainty about the extent of disease on pre-operative imaging, staged approach of reconstruction with CWPF could be considered [40,41]. This involves performing a wide local excision and saline fill of the cavity, followed by second stage reconstruction after confirming tumour extent and achieving clear margins.

Skin island on the flap is used to reconstruct areola while nipple could be reconstructed either in the immediate or delayed setting. Patients could then have areolar tattooing to improve the aesthetics [56]. Following-up patients with these flaps has not shown any significant flap atrophy after radiotherapy, although the data is limited by short-term follow-up [54, 55].

It is important to assess the impact on radiotherapy planning as some of these reconstruction patterns could add to the complexity of radiotherapy planning. All cases presented in this article had radiotherapy after the surgery. There was no interference reported by oncology colleagues in radiotherapy planning. Our centre practices CT planning for radiotherapy and the flap layout is clearly demonstrated on the cross section (Figure 3). It is, however, important that the tumour bed is marked clearly with clips during surgery to help the radiation oncologist demarcate the area for the tumour bed boost, if needed. If there is any doubt, it is helpful that the oncologist consults their surgical colleague to understand the flap layout and avoid overestimating the area for the tumour bed boost. A recent study shows that a surgeon working together closely with a radiation oncologist can more accurately define the tumour bed boost [57]. The tumour bed clips can at times become displaced by the time of radiation therapy planning [58]. An analysis of 1,933 patients showed that the use of local boost radiation therapy and tumour bed marking was not reported in the majority of studies of oncoplastic BCS [59].

The described approach to reconstruct central breast defect in small to moderate sized non-ptotic breasts using a CWPF offers an additional surgical option in women keen to avoid mastectomy. Patient selection is based on the extent of tumour, size of breast, degree of ptosis and presence of redundant lateral chest wall fold. They should however be warned of mastectomy, if the disease is more extensive than anticipated on initial imaging.

Our case series lacks the patient related outcome measure data, given the small sample size. All patients were pleased to avoid mastectomy and were happy with the aesthetic outcome of the breast as judged between 1 and 2 years after radiotherapy. 


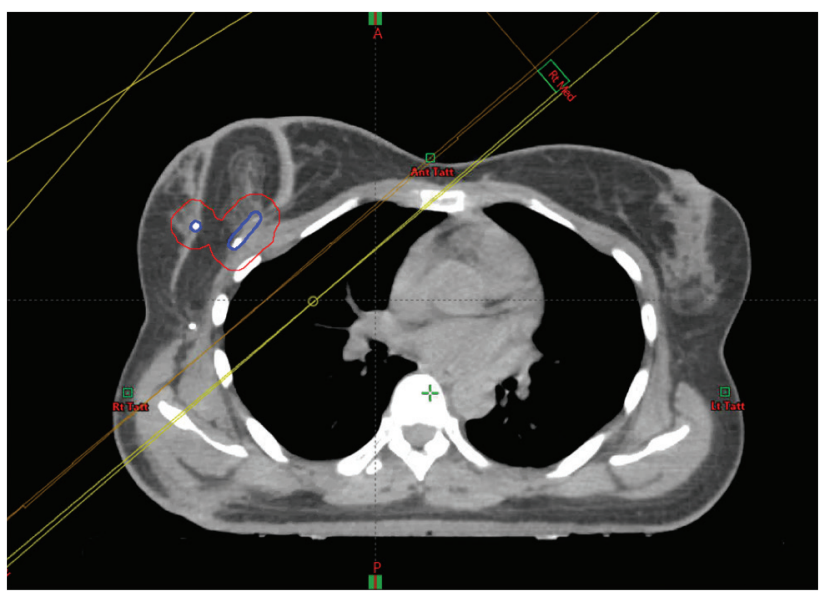

Figure 3. Radiotherapy planning scan of case 3. The tumour bed clips have been identified with the assistance of the surgeon and outlined (in blue) and a $1 \mathrm{~cm}$ margin added to create a planning target volume (in red).

\section{Conclusion}

Partial breast reconstruction with CWPF and areolar reconstruction (with or without nipple reconstruction) provides an alternative surgical option for central breast tumours in small to moderate non-ptotic breast. This is the first report described in the literature. Our series have shown excellent aesthetic results in the short-term follow-up period after radiotherapy. This approach obviates the need for mastectomy and potentially for contralateral symmetrisation, as this intervention aims to restore the breast to its pre-treatment size.

\section{List of abbreviations}

CWPF, Chest wall perforator flap; DCIS, Ductal carcinoma in-situ; BCS, Breast conserving surgery; OBS, Oncoplastic breast surgery; LICAP, Lateral intercostal artery perforators; LTAP, Lateral thoracic artery perforator; ER, Oestrogen receptor; PR, Progesterone receptor.

\section{Compliance with ethical standards}

\section{Statement of human and animal rights}

This study was carried out in line with clinical protocols with approval by the local hospital ethics committee (number 4317).

\section{Informed consent}

For this type of study, formal consent is not required.

\section{Disclosures of potential conflicts of interest}

The authors declare that they have no conflicts of interest to disclose. 


\section{Evidence-based medicine}

\section{Level of evidence}

Level V, Case Series.

\section{Funding declaration}

No funding received.

\section{Referencs}

1. Veronesi U, Cascinelli N, and Mariani L, et al (2002) Twenty-year follow-up of a randomized study comparing breast-conserving surgery with radical mastectomy for early breast cancer N Engl J Med 347(16) 1227-1232 https://doi.org/10.1056/NEJMoa020989 PMID: 12393819

2. Fisher B, Anderson S, and Bryant J, et al (2002) Twenty-year follow-up of a randomized trial comparing total mastectomy, lumpectomy, and lumpectomy plus irradiation for the treatment of invasive breast cancer N Engl J Med 347(16) 1233-1241 https://doi.org/10.1056/ NEJMoa022152 PMID: 12393820

3. Simone NL, Dan T, and Shih J, et al (2012) Twenty-five year results of the national cancer institute randomized breast conservation trial Breast Cancer Res Treat 132(1) 197-203 https://doi.org/10.1007/s10549-011-1867-6

4. Lichter AS, Lippman ME, and Danforth DN, et al (1992) Mastectomy versus breast-conserving therapy in the treatment of stage I and II carcinoma of the breast: a randomized trial at the National Cancer Institute J Clin Oncol 10(6) 976-983 https://doi.org/10.1200/ JCO.1992.10.6.976 PMID: 1588378

5. Lagendijk M, van Maaren MC, and Saadatmand S, et al (2018) Breast conserving therapy and mastectomy revisited: breast cancerspecific survival and the influence of prognostic factors in 129,692 patients Int J Cancer 142(1) 165-175 https://doi.org/10.1002/ ijc.31034

6. Engel J, Kerr J, and Schlesinger-Raab A, et al (2004) Quality of life following breast-conserving therapy or mastectomy: results of a 5-year prospective study Breast J 10(3) 223-231 https://doi.org/10.1111/j.1075-122X.2004.21323.x PMID: 15125749

7. Clough KB, and Baruch J (1992) Plastic surgery and conservative treatment of breast cancer. Indications and results Ann Chir Plast Esthet 37(6) 682-692 http://www.ncbi.nlm.nih.gov/pubmed/1340172 Date accessed: 24/02/20 PMID: 1340172

8. Audretsch W, Rezai M, and Kolotas C, et al (1998) Tumor-specific immediate reconstruction in breast cancer patients Semin Plast Surg 11(01) 71-100 https://doi.org/10.1055/s-2008-1080243

9. Audretsch WP (1994) Onco-plastic surgery: "target" volume reduction (BCT-mastopexy), lumpectomy reconstruction (BCT-reconstruction) and flap-supported operability in breast cancer Proc 2nd European Congress on Senology (Oct: 1994) (Vienna/Bologna: Moncuzzi) pp 139-157

10. De La Cruz L, Blankenship SA, and Chatterjee A, et al (2016) Outcomes after oncoplastic breast-conserving surgery in breast cancer patients: a systematic literature review Ann Surg Oncol 23(10) 3247-3258 https://doi.org/10.1245/s10434-016-5313-1 PMID: $\underline{27357177}$ 
11. Chand ND, Browne V, and Paramanathan N, et al (2017) Patient-reported outcomes are better after oncoplastic breast conservation than after mastectomy and autologous reconstruction Plast Reconstr Surg - Glob Open 5(7) e1419 https://doi.org/10.1097/ GOX.0000000000001419 PMID: 28831358 PMCID: 5548581

12. Clough KB, Lewis JS, and Couturaud B, et al (2003) Oncoplastic techniques allow extensive resections for breast-conserving therapy of breast carcinomas Ann Surg 237(1) 26-34 https://doi.org/10.1097/00000658-200301000-00005

13. Kelsall JE, McCulley SJ, and Brock L, et al (2017) Comparing oncoplastic breast conserving surgery with mastectomy and immediate breast reconstruction: case-matched patient reported outcomes J Plast Reconstr Aesthetic Surg 70(10) 1377-1385 https://doi. org/10.1016/j.bjps.2017.05.009

14. De Lorenzi F, Di Bella J, and Maisonneuve P, et al (2018) Oncoplastic breast surgery for the management of ductal carcinoma in situ (DCIS): is it oncologically safe? A retrospective cohort analysis Eur J Surg Oncol 44(7) 957-962 https://doi.org/10.1016/j.ejso.2018.04.015 PMID: 29759643

15. Multon O, Bourgeois D, and Validire P, et al (1997) Breast cancers with central localization: conservative treatment by tumorectomy with ablation of the areolar plaque Presse Med 26(21) 988-994 PMID: 9239144

16. Fitzal F, Nehrer G, and Hoch D, et al (2007) An oncoplastic procedure for central and medio-cranial breast cancer Eur J Surg Oncol 33(10) 1158-1163 https://doi.org/10.1016/j.ejso.2007.04.004 PMID: 17532171

17. Fowble B, Solin LJ, and Schultz DJ, et al (1992) Breast recurrence and survival related to primary tumor location in patients undergoing conservative surgery and radiation for early-stage breast cancer Int J Radiat Oncol Biol Phys 23(5) 933-939 https://doi. org/10.1016/0360-3016(92)90897-Q PMID: 1322386

18. Sisti A, Huayllani MT, and Boczar D, et al (2020) Breast cancer in women: a descriptive analysis of the national cancer database Acta Biomed 91(2) 332-341 PMID: 32420970 PMCID: 7569667

19. Lim RJ, Lee KS, and Lee SH, et al (2010) Central lumpectomy with resection of the nipple-areolar complex for retroareolar or central breast cancers J Korean Surg Soc 79(4) 275-280 https://doi.org/10.4174/jkss.2010.79.4.275

20. Wagner E, Schrenk P, and Huemer GM, et al (2007) Central quadrantectomy with resection of the nipple-areola complex compared with mastectomy in patients with retroareolar breast cancer Breast J 13(6) 557-563 https://doi.org/10.1111/j.1524-4741.2007.00492.x PMID: 17983395

21. Simmons RM, Brennan MB, and Christos $P$, et al (2001) Recurrence rates in patients with central or retroareolar breast cancers treated with mastectomy or lumpectomy Am J Surg 182(4) 325-329 https://doi.org/10.1016/S0002-9610(01)00721-8 PMID: 11720664

22. Vyas JJ, Chinoy RF, and Vaidya JS (1998) Prediction of nipple and areola involvement in breast cancer Eur J Surg Oncol 24(1) 15-16 https://doi.org/10.1016/S0748-7983(98)80117-0 PMID: 9542508

23. Foersterling E, Golatta M, and Hennigs A, et al (2014) Predictors of early poor aesthetic outcome after breast-conserving surgery in patients with breast cancer: initial results of a prospective cohort study at a single institution J Surg Oncol 110(7) 801-806 https://doi. org/10.1002/jso.23733 PMID: 25132148

24. Grisotti A (1994) Immediate reconstruction after partial mastectomy Oper Tech Plast Reconstr Surg 1(1) 1-12 https://doi.org/10.1016/ S1071-0949(10)80013-7

25. Buller M, Heiman A, and Davis J, et al (2017) Immediate breast reconstruction of a nipple areolar lumpectomy defect with the L-flap skin paddle breast reduction design and contralateral reduction mammoplasty symmetry procedure: optimizing the oncoplastic surgery multispecialty approach Eplasty 17 e14 PMID: 28416989 PMCID: 5379251

26. Moustafa A, and Fakhr I (2014) Outcome of different oncoplastic surgical (OPs) techniques for centrally located breast cancer (CLBC) J Egypt Natl Canc Inst 26(4) 203-209 https://doi.org/10.1016/j.jnci.2014.10.003 PMID: 25467388 
27. Holmes DR, Schooler W, and Smith R (2011) Oncoplastic approaches to breast conservation Int J Breast Cancer 2011303879 https:// doi.org/10.4061/2011/303879

28. Naguib SF (2006) Oncoplastic resection of retroareolar breast cancer: central quadrantectomy and reconstruction by local skin-glandular flap J Egypt Natl Canc Inst 18(4) 334-347 http://www.ncbi.nlm.nih.gov/pubmed/18301457 Date accessed: 15/03/20

29. Della Rovere GQ, Pillarisetti RR, and Bonomi R, et al (2007) Oncoplastic surgery for retro areolar breast cancer - a technical modification of the grisotti flap Indian J Surg 69(4) 160-162 https://doi.org/10.1007/s12262-007-0012-6 PMID: 23132973 PMCID: 3452462

30. Galimberti V, Zurrida S, and Luini A, et al (1993) Central small size breast cancer: how to overcome the problem of nipple and areola involvement Eur J Cancer 29(8) 1093-1096 https://doi.org/10.1016/S0959-8049(05)80294-1

31. McCulley SJ, Durani P, and Macmillan RD (2006) Therapeutic mammaplasty for centrally located breast tumors Plast Reconstr Surg 117(2) 366-373 https://doi.org/10.1097/01.prs.0000200874.31320.c2 PMID: 16462314

32. McCulley SJ, and Macmillan RD (2005) Planning and use of therapeutic mammoplasty - Nottingham approach Br J Plast Surg 58(7) 889-901 https://doi.org/10.1016/j.bjps.2005.03.008 PMID: 16043150

33. Losken A, Elwood ET, and Styblo TM, et al (2002) The role of reduction mammaplasty in reconstructing partial mastectomy defects Plast Reconstr Surg 109(3) 968-975 https://doi.org/10.1097/00006534-200203000-00025 PMID: 11884818

34. Clough KB, Nos C, and Salmon RJ, et al (1995) Conservative treatment of breast cancers by mammaplasty and irradiation: a new approach to lower quadrant tumors Plast Reconstr Surg 96(2) 363-370 https://doi.org/10.1097/00006534-199508000-00015 PMID: 7624409

35. Holmström H, and Lossing C (1986) The lateral thoracodorsal flap in breast reconstruction Plast Reconstr Surg 77(6) $933-941$ https:// doi.org/10.1097/00006534-198606000-00010 PMID: 3714889

36. Hamdi M, Van Landuyt K, and Monstrey S, et al (2004) Pedicled perforator flaps in breast reconstruction: a new concept Br J Plast Surg 57(6) 531-539 https://doi.org/10.1016/j.bjps.2004.04.015 PMID: 15308400

37. Hamdi M, Van Landuyt K, and Hijjawi JB, et al (2008) Surgical technique in pedicled thoracodorsal artery perforator flaps: a clinical experience with 99 patients Plast Reconstr Surg 121(5) 1632-1641 https://doi.org/10.1097/PRS.0b013e31816c3bfa PMID: 18453987

38. Hamdi M, Van Landuyt K, and de Frene B, et al (2006) The versatility of the inter-costal artery perforator (ICAP) flaps J Plast Reconstr Aesthetic Surg 59(6) 644-652 https://doi.org/10.1016/j.bjps.2006.01.006

39. McCulley SJ, Schaverien M V, and Tan VKM, et al (2015) Lateral thoracic artery perforator (LTAP) flap in partial breast reconstruction J Plast Reconstr Aesthetic Surg 68(5) 686-691 https://doi.org/10.1016/j.bjps.2015.01.008

40. Roy PG, and Tenovici AA (2017) Staged approach to partial breast reconstruction to avoid mastectomy in women with breast cancer Gland Surg 6(4) 336-342 https://doi.org/10.21037/gs.2017.03.08 PMID: 28861373 PMCID: 5566661

41. Roy PG (2016) One-stage vs. two-stage approach for partial breast reconstruction with lateral chest wall perforator flaps Cancer Treat Res Commun 9 56-61 https://doi.org/10.1016/j.ctarc.2016.06.003

42. Goyal A The POSNOC Trial POsitive Sentinel NOde: Adjuvant Therapy Alone Versus Adjuvant Therapy Plus Clearance or Axillary Radiotherapy http://www.posnoc.co.uk/ Date accessed: 13/04/20

43. Kijima Y, Yoshinaka H, and Shinden Y, et al (2014) Oncoplastic breast surgery for centrally located breast cancer: a case series Gland Surg 3(1) 62-73 PMID: 25083497 PMCID: 4115775

44. Chirappapha P, Sukpanich R, and Sukarayothin T, et al (2017) Inferior dermoglandular flap for central quadrantectomy in non-ptosis breast cancer patients AME Med J 2(10) 20 https://doi.org/10.21037/amj.2017.02.01

45. Clough KB, Kaufman GJ, and Nos C, et al (2010) Improving breast cancer surgery: a classification and quadrant per quadrant atlas for oncoplastic surgery Ann Surg Oncol 17(5) 1375-1391 https://doi.org/10.1245/s10434-009-0792-y PMID: 20140531 
46. Noguchi M, Taniya T, and Miyazaki I, et al (1990) Immediate transposition of a latissimus dorsi muscle for correcting a postquadrantectomy breast deformity in Japanese patients Int Surg 75(3) 166-170 http://www.ncbi.nlm.nih.gov/pubmed/2242969 Date accessed: 15/03/20 PMID: 2242969

47. Navin C, Agrawal A, and Kolar KM (2007) The use of latissimus dorsi miniflap for reconstruction following breast-conserving surgery: experience of a small breast unit in a district hospital World J Surg 31(1) 40-50 https://www.researchgate.net/publication/6618840 The_Use_of_Latissimus_Dorsi_Miniflap_for_Reconstruction_Following_Breast-conserving_Surgery_Experience_of_a_Small_Breast_ Unit_in_a_District_Hospital Date accessed: 15/03/20 https://doi.org/10.1007/s00268-006-0396-7

48. Clough KB, Cuminet J, and Fitoussi A, et al (1998) Cosmetic sequelae after conservative treatment for breast cancer: classification and results of surgical correction Ann Plast Surg 41(5) 471-481 https://doi.org/10.1097/00000637-199811000-00004 PMID: 9827948

49. Raja MAK, Straker VF, and Rainsbury RM (1997) Extending the role of breast-conserving surgery by immediate volume replacement $\mathrm{Br}$ J Surg 84(1) 101-105 PMID: 9043470

50. Rainsbury RM, and Paramanathan N (1998) Recent progress with breast-conserving volume replacement using latissimus dorsi miniflaps in UK patients Breast Cancer 5(2) 139-147 https://doi.org/10.1007/BF02966686

51. De Lorenzi F, Corso G, and Botta F, et al (2020) Immediate breast reconstruction with latissimus dorsi flap for patients with local recurrence of breast cancer Eur J Surg Oncol 46(6) 1013-1020 https://doi.org/10.1016/j.ejso.2020.01.015 PMID: 31955994 PMCID: 7180348

52. Zaha H (2015) Oncoplastic volume replacement technique for the upper inner quadrant using the omental flap Gland Surg 4(3) 263-269 PMID: 26161311 PMCID: 4461710

53. Munhoz AM, Montag E, and Arruda E, et al (2011) Immediate conservative breast surgery reconstruction with perforator flaps: new challenges in the era of partial mastectomy reconstruction? Breast 20(3) 233-240 https://doi.org/10.1016/j.breast.2011.01.001 PMID: 21292485

54. Hu J, Cuffolo G, and Parulekar V, et al (2019) The results of surveillance imaging after breast conservation surgery and partial breast reconstruction with chest wall perforator flaps; a qualitative analysis compared with standard breast-conserving surgery for breast cancer Clin Breast Cancer 19(3) e422-e427 https://doi.org/10.1016/j.clbc.2019.01.010 PMID: 30797681

55. Hu J, Tenovici A, and Parulekar $\mathrm{V}$, et al (2018) The impact of partial breast reconstruction with lateral chest wall perforator flaps on post-operative cancer surveillance Ann Breast Surg 2 10-10 https://doi.org/10.21037/abs.2018.04.01

56. Sisti A (2020) Nipple-areola complex reconstruction Medicina 56(6) 1-8 https://doi.org/10.3390/medicina56060296

57. Garreffa E, Hughes-Davies L, and Russell S, et al (2020) Definition of tumor bed boost in oncoplastic breast surgery: an understanding and approach Clin Breast Cancer 20 e510-e515 https://doi.org/10.1016/j.clbc.2020.03.003 PMID: 32284305

58. Aribal E, Demircioglu O, and Olduz M, et al (2015) Do surgical clips really indicate the tumor bed margins for radiotherapy planning? J Clin Oncol 33(15_suppl) e12067-e12067 https://doi.org/10.1200/jco.2015.33.15_suppl.e12067

59. Schaverien MV, Stallard S, and Dodwell D, et al (2013) Use of boost radiotherapy in oncoplastic breast-conserving surgery - a systematic review Eur J Surg Oncol 39(11) 1179-1185 https://doi.org/10.1016/j.ejso.2013.07.240 PMID: 23988230 